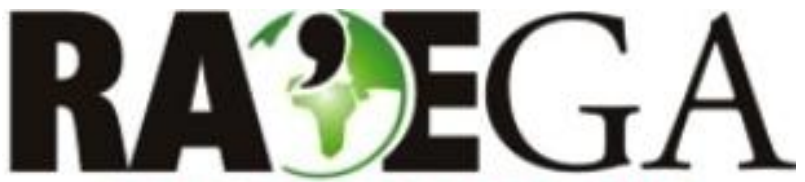

O ESPACO GEOGRÁFICO EM ANÁLISE

\title{
O MAPA COMO CRIAÇÃO DE RESISTÊNCIAS
}

\section{THE MAP AS CREATION OF RESISTANCES}

\author{
Karina Rousseng Dal Pont \\ Doutoranda em Educação pela Universidade Federal de Santa Catarina \\ Florianópolis, SC \\ e-mail: karinardalpont@gmail.com
}

\section{Recebido em: 02.10.2013}

Aceito em: 23.11.2014

\section{Resumo}

O presente texto apresenta uma pesquisa em educação em desenvolvimento, cujo tema é o ensino de cartografia e a arte contemporânea. A partir da leitura do livro $A$ descoberta da lentidão, de Stan Nadolny (1989) e do diálogo com as obras Buenos Aires Tour, Jorge Macchi (2004), Body Builders de Alex Flemming (2001) e o vídeo Global Safari (Powered by Google) de Renata Marquez e Wellington Cançado (2009), a arte contemporânea é considerada ferramenta que atua diante das impossibilidades dos mapas. Nesta pesquisa, às formas como a cartografia é ensinada nas escolas, e/ou os aparatos de verdade que a cartografia apresenta nos ambientes de ensino são considerados um problema. Assim, a partir da investigação junto aos processos de criação de artistas contemporâneos que utilizam a base cartográfica como parte de suas obras, experimenta-se o mapa como criação de resistências no sentido deleuziano. O caminho investigativo escolhido foi inventar formas de rasurar os mapas, tratando-o não como fórmulas prontas ou dadas sobre o espaço, mas ir além das suas funções de leitura e comunicação. O texto apresenta uma experiência realizada com professoras em formação da $7^{\underline{a}}$ fase do Curso de Pedagogia da Universidade do Estado de Santa Catarina pelo centro histórico da cidade de Florianópolis. Trata-se de uma proposta investigativa criada a partir da obra Buenos Aires Tour de Jorge Macchi (2004). O trabalho em andamento deseja abrir o que é aprisionado no ensino de cartografia na escola e busca máquinas de pensar, significar e produzir outros sentidos para a cartografia na educação básica e no ensino superior.

Palavras-chave: cartografia; arte contemporânea; educação. 


\begin{abstract}
This paper presents a research on education in progress, whose theme is the teaching of cartography and contemporary art. Based on the novel Die Entdeckung der Langsamkeit and also by the approach to the artistical works Tour Buenos Aires by Jorge Macchi (2004), Body Builders by Alex Flemming (2001) and the Global Safari video (Powered by Google) by Renata Marquez and Wellington Cançado (2009), contemporary art can be considered a tool that operates on the impossibilities of the maps. In this study, it is considered a problem how cartography can be taught at schools and/or the real apparatus that cartography can offer in educational settings. Thus, through the investigation of creative processes used by contemporary artists, who use a cartographic basis as part of their works, it is possible to experiment the map as creating resistance in a deleuzian sense. The investigative path chosen was to create different forms to change the maps, treating them not as ready formulas about space and location, but as endeavor to go beyond their reading and communication functions. The paper presents an experiment conducted in the historic city center of Florianópolis with teachers from the seventh semester of a training program in education at the University of the State of Santa Catarina. This is an investigative proposal created through the work Buenos Aires Tour by Jorge Macchi (2004). The work in progress aims to open what is trapped into the teaching of cartography at school. Therefore, there is a search for "thinking machines" in order to produce other senses for cartography in basic and higher education.
\end{abstract}

Keyword: cartography; contemporary art; education.

\title{
PREÂMBULOS
}

Viajaram em águas fora da Europa onde se tratava apenas de observar bons mapas. O lindo mundo estrangeiro - realmente tinha que ver esse mundo, senão nunca mais acreditaria nele. $O$ próprio mar tiraria John Franklin do desânimo. [...] No início das aulas de navegação, Matthew, o capitão do navio, declarara que ele não acreditava que alguém no mundo pudesse realizar algo de bom sem conhecer as estrelas pela posição e pelo nome. [...] John Franklin gostava de contemplar os mapas terrestres e marítimos. Examinavaos por muito tempo até achar que compreendera cada traço e todas as formas da terra nessa região. "Um mapa é, em princípio, uma coisa impossível", dissera Matthew, "pois eles convertem elevações em planícies" (NADOLNY, 1989, p.38).

\section{INTRODUÇÃO}

Neste romance alemão, o grande enredo se desenvolve a partir da biografia de um dos maiores navegadores do século XIX, o inglês John Franklin, e das expedições que ele realizou para o Polo Norte em busca da Passagem Noroeste. A 
partir do trecho escolhido para abrir este texto, percebem-se a necessidade daqueles que se aventuravam em águas distantes da costa de dominar as medidas exatas do espaço em alto-mar e o encantamento de um aspirante com a exatidão dessas medições. Todavia, as formas exatas, por meio das quais os mapas representavam o espaço, apresentada por Matthew, capitão da primeira expedição da qual John Franklin participou, demonstram as impossibilidades de um mapa, pois “convertem elevações em planícies" (NADOLNY, 1989, p.38).

Diante da impossibilidade do mapa, foram escolhidas três obras de arte contemporâneas como meio de apresentar o espaço como criação e o mapa como resistência. Pois concordamos com Deleuze, ao afirmar que "a arte consiste em libertar a vida que o homem aprisionou. O homem não para de aprisionar a vida, de matar a vida [...] o artista é quem libera uma vida potente, uma vida mais do que pessoal. [...] Liberar a vida das prisões, e isso é resistir" (RIEUX, s/d). ${ }^{1}$

O diálogo com as obras e com Deleuze abre o presente texto que trata sobre fragmentos de uma pesquisa de doutorado em educação, em que a cartografia escolar e os modos como é ensinada torna-se um problema, ou seja, uma "prisão". Consideramos o ensino de cartografia um problema pelas incompreensões em seus meios de ensino, ou pelos modos como representa o espaço, por aquilo que aprisiona. E neste sentido o conceito de resistência de Gilles Deleuze (RIEUX, s/d) atua nesta pesquisa como possibilidade de inventar outros modos de ensinar a cartografia na escola. Não se trata de negar a cartografia oficial, mas de abri-la a outras possibilidades de criação para além da interpretação das informações que são apresentadas pelo mapa em sala de aula.

No conjunto da obra do artista portenho Jorge Macchi as relações com a cartografia se fazem presentes em muitos de seus trabalhos e provocam no leitor estranhezas ao subtrair das cartas e mapas as referências da cartografia oficial, como legendas e escala, proporcionando, assim, outros modos de leitura do espaço. Assim, observa-se na figura 1, Buenos Aires Tour de Jorge Macchi, que a partir da perfuração em uma placa de vidro foram "rasgadas" oito linhas que coloridas e

\footnotetext{
1 Veja L'ABÉCÉDAIRE de Gilles Deleuze. Entrevista com Claire Parnet. Direção: Pierre-André Boutang. França: Montparnasse. Documentário. Vídeo, 1996. 480 min.
} 
sobrepostas a um mapa de Buenos Aires, produziram deslocamentos ante a impossibilidade do mapa, apontada pelo capitão Matthew no romance de Sten Nadolny. A partir dessas oito linhas foi construído um roteiro no qual 46 pontos de interesse sobre a cidade de Buenos Aires são apresentados de forma diferente daquela que os guias turísticos habitualmente utilizam para apresentar as partes conhecidas da cidade (PEREZ-BARREIRO, 2007, figura 1): cartões-postais, imagens, textos, músicas, entre outros elementos, foram elaborados e/ou encontrados ao longo dos trajetos para a construção desse roteiro. Nestas composições, ao estabelecer links entre pontos diversos da cidade através de imagens que se repetem em suas diferentes localidades, criam-se outras formas de entrar na cidade de Buenos Aires pelo mapa.

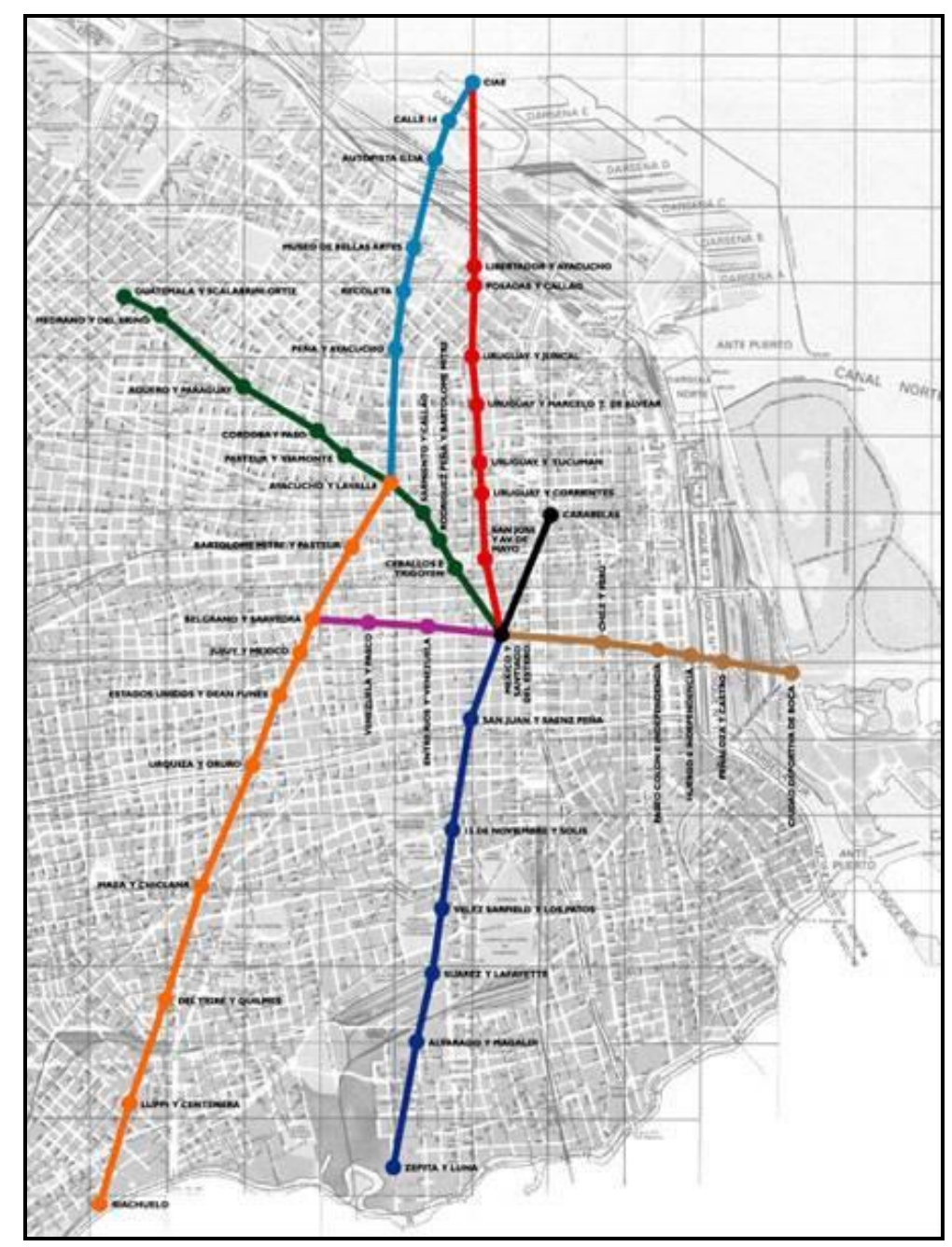

Figura 1 - Mapa que integra o livro de Jorge Macchi, Buenos Aires Tour, 2004. Fonte: Jorge Macchi (blog do autor) ${ }^{2}$

\footnotetext{
${ }^{2}$ http://www.jorgemacchi.com/es/obras/30/buenos-aires-tour
} 
Quatro telas formam um painel onde o mapa da região de Chiapas, no sul do México, está reproduzido sobre o dorso de um homem seminu. Mas, por que reproduzir num abdômen perfeito um mapa, professora? - pergunta uma aluna do curso de Pedagogia da Universidade do Estado de Santa Catarina (UDESC) diante da obra (figura 2), de Alex Flemming, exposta na Pinacoteca do Estado de São Paulo, no ano de 2010.

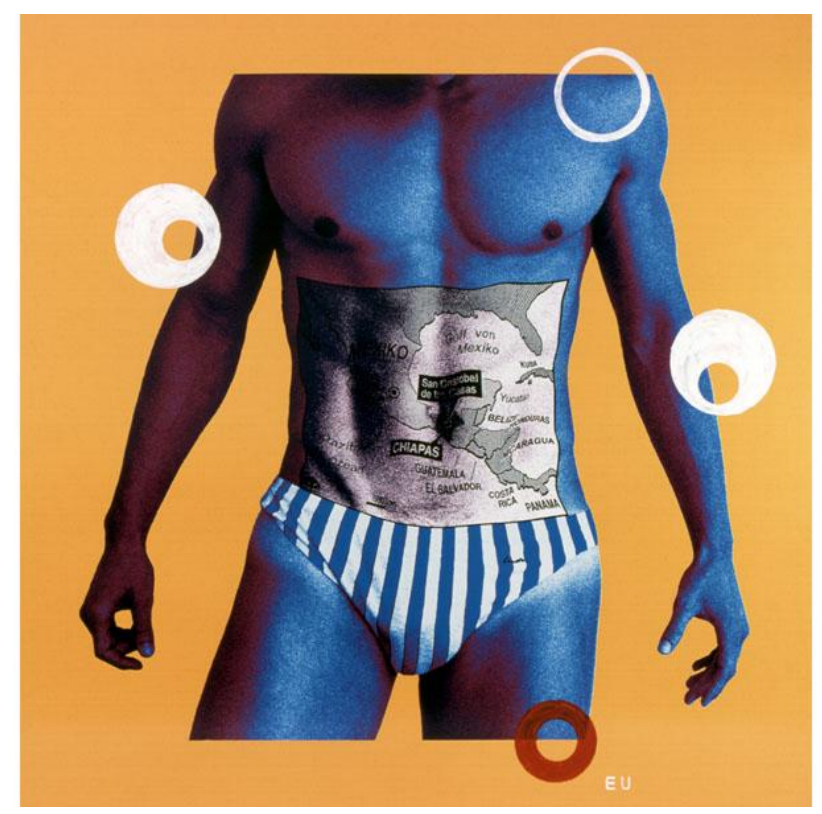

Figura 2 - Sem Título, série Body Builders (2001-2002), Alex Flemming. Fonte: Alex Flemming (site do autor) ${ }^{3}$

Na obra, a sobreposição de áreas de conflito, inscritas em partes de corpos bem definidos, nos permite ampliar a leitura sobre questões que envolvem limites e fronteiras entre estados, países, regiões que não cabem na exatidão do modelo normativo da cartografia científica. Trata-se de mapear fronteiras indefinidas. No caso da figura 2 vemos o estado de Chiapas, localizado no sul do México, que conta com a presença dos rebeldes do Exército Zapatista de Libertação Nacional/ZLN, o que desestabiliza as questões sociais e políticas desta região. O espaço nos é apresentado de outra forma, não mais como uma superfície lisa, plana e exata. A partir das dobras que o relevo do corpo dá ao mapa, pode-se estabelecer outro diálogo com a cartografia e sua inquestionável função de representar com exatidão qualquer superfície do planeta.

\footnotetext{
${ }^{3}$ http://www.alexflemming.com/
} 
Nesta série, denominada Body Builders (2001/2002), o artista brasileiro Alex Flemming reproduz em partes bem definidas dos corpos mapas de áreas marcadas por conflitos territoriais, justamente indefinidas (Faixa de Gaza, no Oriente Médio, Índia e Paquistão, Sarajevo, na Península dos Balcãs, entre outros). Toda a exatidão de uma fronteira se desfaz mediante as instabilidades políticas, econômicas e sociais destas regiões e também diante da instabilidade dos corpos que, pelo simples movimento da respiração, mobilizam os elementos fixos que o mapa representa.

A produção audiovisual, Global Safari (Powered by Google) de Renata Marquez e Wellington Cançado abre ao espectador a possibilidade de viajar em 12 minutos por diversas cidades do mundo via Google Earth. A construção de um roteiro bem elaborado e a trilha sonora escolhida nos remete a origem dos lugares por meio das frases e idiomas presentes em cada espaço/lugar visitado. Porém, a reflexão dos pesquisadores, para além de uma inocente e breve viagem em diferentes escalas, recai sobre a questão das "paisagens de vigilância", do controle da ferramenta Google (que passa por uma agência militar americana) e a identificação de "Espaços de Miopia" do Google Earth, cujo índice mede, de acordo com os autores, "a nebulosidade do caráter público do território do Google Earth, uma vez que ele é universalmente acessível, mas filtrável a partir de um lugar de controle" (MARQUEZ; CANÇADO, 2009, p. 547).

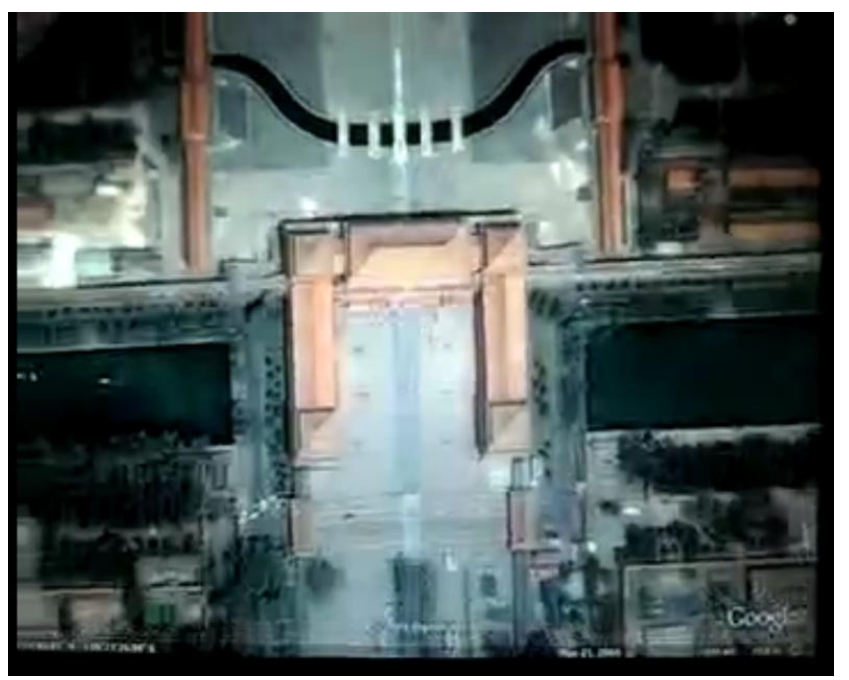

Figura 3 - Frame do video Global Safari (Powered by Google) ${ }^{4}$

${ }^{4}$ GLOBAL Safari (Powered by Google). Direção: Renata Moreira Marquez e Wellington Cançado. Brasil. Vídeo, 2009.12 min. Disponível em http://vimeo.com/5175377 
As três obras apresentadas rasuram o mapa. Na obra Buenos Aires Tour (figura 1) a subtração de elementos da cartografia oficial, como legendas, escalas, fonte, nos faz entrar na cidade de outras formas. Na obra Body Builders (figura 2) a exatidão das fronteiras entre territórios se desfaz mediante a projeção dos mapas em corpos humanos, instáveis pelo simples fato da respiração deslocar elementos fixos que se deseja manter numa área de fronteira territorial. O vídeo Global Safari (Powered by Google) (figura 3), pela apresentação de "espaços de miopia" e meios de controle, permite uma reflexão sobre a substituição da tecnologia nas formas de dizer a verdade absoluta sobre o espaço. Dessa forma as rasuras abrem espaço para questionamentos sobre os aprisionamentos que os mapas oficiais produzem em seus leitores. Esse é um dos pontos de partida para a escrita deste texto: como a arte contemporânea pode mobilizar pensamentos, sensações e criar outras experiências com a cartografia e seus modos de ensino?

Neste texto, será apresentado num primeiro momento como se chega a um problema de pesquisa e como se realizam as aproximações estabelecidas entre a arte contemporânea e o ensino de cartografia. Num segundo momento será apresentado o caminho metodológico da pesquisa a partir de uma experiência realizada com um grupo de professoras em formação da $7^{\underline{a}}$ fase do Curso de Pedagogia da Universidade do Estado de Santa Catarina (UDESC) pelo centro histórico da cidade Florianópolis. Trata-se de uma proposta investigativa criada a partir da obra Buenos Aires Tour, do artista portenho Jorge Macchi, como criação de outros modos de apresentar e compreender um pedaço da cidade e as formas de mapeá-lo. E, por fim, apresentaremos a análise preliminar dos dados coletados e as considerações sobre o processo da pesquisa que se encontra em desenvolvimento.

\section{DESENVOLVIMENTO: DO ENCONTRO COM A CARTOGRAFIA ESCOLAR E A ARTE CONTEMPORÂNEA}

A impossibilidade do mapa será tomada a partir da constatação de que a cartografia científica, pela força que possui em sua perspectiva vertical de representar o espaço, provoca achatamentos ao tornar os relevos, depressões, movimentos de crosta, sensações e dinâmicas, tudo que é vivo na superfície da Terra, em elementos estáticos. Ao fazê-lo, imobiliza a formação de um pensamento 
espacial, conferindo aos mapas oficiais a verdade sobre as formas de apresentar 0 espaço, dando a impressão de que este é apenas uma superfície, uma "esfera de uma completa horizontalidade" (MASSEY, 2008, p.160). Deste modo, ela oblitera pela força da ordem as subjetividades humanas, igualmente necessárias aos processos de produção, apresentação e compreensão do espaço ${ }^{5}$. Ou seja, as relações que os sujeitos criam através das experiências cotidianas com as ruas, os monumentos, as praças, as esquinas, os relevos, são, na sua maioria, negligenciadas pelo mapa oficial.

A discussão sobre a fabricação de verdades ensejada pela produção cartográfica mais cartesiana sobre o espaço se desloca para o contexto escolar, considerando o processo de iniciação cartográfica como mais um meio que tende a limitar os sentidos da cartografia e dos processos de compreensão do espaço.

O ensino da cartografia nas escolas deriva de uma ideia cartesiana e positivista de tomar o espaço como superfície lisa, e a imagem reproduzida nos mapas utilizados em sala de aula como verdade e única forma de representar o espaço.

Em termos gerais, de acordo com alguns teóricos vinculados à geografia da percepção (TUAN, 1980; 1983; OLIVEIRA, 1999), a criança vive e percebe o espaço desde a barriga da mãe, razão pela qual caberia perguntar: por que, então, priorizamos ao longo da formação escolar da criança a instrumentalização das formas de ler o espaço ao invés de provocarmos a formação de um pensamento sobre estes modos de representá-lo? Desde a educação infantil, através das brincadeiras entre si e com os objetos que as rodeiam, as crianças estabelecem relações com o espaço. Deslocam-se, engatinham, exploraram os espaços da casa, da creche, da rua, erguem o corpo, caminham, correm, enfim, experimentam livremente o espaço. Porém, ao ingressar nos anos iniciais do ensino fundamental o processo de alfabetização põe em jogo não somente um disciplinamento do corpo, mas também dos modos de produzir um pensamento sobre o espaço:

\footnotetext{
${ }^{5}$ Neste texto, utilizo o termo "representação do espaço" relacionado à cartografia, com todos os seus aparatos de legitimidade: legendas, escala, símbolos etc.; e o termo "apresentação do espaço" indicando o rumo para outras cartografias, para além da oficial, ou seja, aquela que escolhemos como outras formas de dizer do espaço, conforme apontado por Oliveira Jr. (2011).
} 
Os desenhos, imaginações do percurso casa-escola, são feitos de acordo com a maneira que o aluno se relaciona com o espaço, porém são, em regra, posteriormente tomados como algo precário, pois não são constituídos com elementos básicos da cartografia formal como norte, visão vertical e escala. O conhecimento da linguagem cartográfica parte deste modo de grafar para negar-lhe a legitimidade de linguagem a falar do espaço (GIRARDI, 2011, p.2).

Essa negação, referida por Girardi (2011), se perpetua durante o Ensino Fundamental e Médio, pois os mapas e suas formas de produção raramente são problematizados em sala de aula - justamente porque os professores entregam aos seus alunos o mapa pronto, à medida que esses chegam pelos materiais didáticos.

Nas experiências realizadas com o mapa e no processo de pesquisa que esta escrita descreve, as obras de Sten Nadolny (1989), Jorge Macchi, Victor Meirelles e Alex Flemming, bem como as pesquisas de Kevin Lynch (1988), Ana Maria Preve (2010), Giseli Girardi (2009), Wenceslao Machado Oliveira Júnior (2009), Doreen Massey (2008) e Renata Marquez (2009) foram fundamentais para investigar a potência de outras linguagens para além da linguagem cartográfica. Visa-se experimentá-las no esforço de criar aberturas na ordem e nas formas dos mapas além de problematizar as formas simplificadas e/ou reduzidas de representação do espaço, implicadas no modo como a cartografia escolar é utilizada em sala de aula. Além disso, objetiva propor possibilidades de multiplicidades de apresentação espacial através de intervenções pedagógicas em ambientes de formação de professores e com alunos do Ensino Fundamental. Com isso, ampliaram-se as maneiras de fazer uma educação em geografia, colocando em relação de suspeita a cartografia escolar e as demais cartografias escolares ou não.

Todavia, o encontro com a arte contemporânea não é o melhor ou o único meio de problematização. Nesta pesquisa, apresenta-se a possibilidade de intervir na cartografia oficial, nos arranjos e representações que ela propõe. Para tanto, a arte é tomada no sentido deleuziano, como criação de outras cartografias e, portanto, como resistência. "E o que é resistir? Criar é resistir [...] é liberar as prisões que o homem cria. [...] Vemos isso claramente no que fazem os artistas. Quer dizer, não há arte que não seja uma liberação de uma força de vida" (RIEUX, s/d). Como já foi anunciado no início do texto, resistir não é se opor à cartografia oficial nem anunciar sua negação, mas antes, de acordo com Paulo Domenech Oneto (2007), como "re- 
existir, se projetar para além do presente, para além de nossas experiências já codificadas, para além de um domínio do possível decidido de antemão nas esferas da moral e da política" (ONETO, 2007, p. 210). Deste modo, a criação de outras cartografias é ao mesmo tempo criação de modos de resistência frente às forças que dominam o fazer cartográfico e os modos como ele é ensinado. Trata-se de construir, pelo sensível, uma poética cartográfica como singularidade, cuja potência desloca coisas/elementos dados no mapa e no modo de pensar sua produção ao "manter-nos ativos em nosso enfrentamento do que parece não querer mudar, ou do que muda muito rapidamente para nós (o caos)" (ONETO, 2007, p.210).

A potência da arte consistiria, então, neste trabalho, em desfazer, na cartografia oficial, tal qual é ensinada nas escolas e fora delas, o que é dado como pronto e acabado, a fim de

\begin{abstract}
fazer fugir o poder domesticador dos mapas escolares, decalques da realidade, para entrar na cartografia (intensiva) e produzir mapas. [...] Não se trata de acabar com a obra mapa e sim colocá-lo sob suspeita e ao lugar que ocupa em nossa sociedade, como uma imagem que tem o poder de dizer de um lugar, de uma distribuição, sobre o poder que tem de dizer a verdade (PREVE, 2010, p.81).
\end{abstract}

\title{
A CARTOGRAFIA ESCOLAR E AS IMPOSSIBILIDADES DO MAPA
}

Esta pesquisa vem se delineando a partir de experiências realizadas, desde agosto de 2009, durante o processo de formação de professores do Curso de Pedagogia (Habilitação Séries Iniciais e Educação Infantil), da Universidade do Estado de Santa Catarina (UDESC), que cursam as disciplinas que a autora ministra na $7^{\text {a }}$ fase destas habilitações, a saber, "Conteúdos e Metodologias de Ensino de Geografia e História" e "A criança, a natureza e a sociedade". E também, nas aulas de geografia que ela vem lecionando na Escola de Educação Básica Irineu Bornhausen em Florianópolis (SC) com turmas do Ensino Fundamental (6ํㅜ e $7^{\circ}$ ano). A imersão na escola e na universidade permite perceber um campo problemático ainda nebuloso para o ensino de geografia no Ensino Fundamental: a cartografia escolar e o processo de iniciação cartográfica.

A cartografia é considerada um problema educacional em função da forma pela qual é trabalhada em contexto escolar, isto é, como uma linguagem que se esgota em si mesma; pelas dificuldades dos professores (não especialistas) em 
compreender os signos cartográficos de representação do espaço; e pela própria estrutura curricular da disciplina, que reduz as possibilidades de experimentação e criação de uma linguagem cartográfica em detrimento da instrumentalização cartográfica. A prática, tanto no Ensino Superior quanto no Ensino Fundamental, instigou uma série de questionamentos: como incitar práticas educativas com mapas de outra forma a fim de superar sua tarefa única de representar o espaço como algo pronto? Como produzir um leitor de mapas para além de uma decodificação técnica da linguagem cartográfica? Como tornar o mapa criação de resistências?

Problematizar as formas simplificadas e reduzidas de representação do espaço pela cartografia escolar são possíveis linhas para pensar a partir da "leitura geográfica das imagens"” (SEEMANN, 2009). Deve-se valorizar as potências do mapa em outras formas de apresentar o espaço ao tratar da produção cartográfica como "linguagem criadora, não apenas como componente comunicativo, mas também, e sobretudo como viabilizadoras de novas produções de mundo" (OLI'VEIRA JÚNIOR; GIRARDI, 2011, p.45).

Ao criar um diálogo entre educação, cartografia e arte possibilita-se a construção de uma linguagem cartográfica que proporciona aos leitores, além das tarefas "oficiais" dos mapas, a formação de "pensamentos acerca do espaço geográfico" (OLIVEIRA JÚNIOR; GIRARDI, 2011, p.45). Pois, a impossibilidade do mapa considerada nesta pesquisa é a sua utilização apenas para representar e comunicar, sendo que muitas vezes essa tarefa não é compreendida em sala de aula justamente pelos aparatos de legitimidade em que o mapa oficial se embasa. Não que ele deixe de comunicar e representar, mas ele deixa de ser compreendido pelos leitores.

É precisar ficar em contato com as obras dos artistas mencionados, acrescido pelas pesquisas derivadas de trabalhos com formação de professores e ainda de trabalhos realizados em outras oportunidades. ${ }^{7}$ Torna-se necessário um

\footnotetext{
${ }^{6}$ Segundo Seemann (2009), numa sociedade que possui um forte interesse na cultura visual e na leitura de imagens, a leitura geográfica das imagens, seria uma leitura que "engloba uma vasta gama de fenômenos materiais e imateriais, processos e produtos, fatos e pensamentos, com uma mensagem que se refere a espaços reais ou imaginários" (SEEMANN, 2009, p.46).

7 Desde 2011, venho atuando em outros espaços de formação, como o curso de formação de professores de Geografia da Rede Municipal de Gaspar (SC), ainda em andamento, e também na
} 
entrosamento com os processos investigativos junto aos materiais didáticos e paradidáticos e aos documentos oficiais que definem o que e como deve ser ensinada a geografia, diante do fato de que a cartografia escolar insiste em ser instrumentalização sobre as formas de ler o espaço. Nesse sentido, é importante buscar intensivamente outros elementos que possam abrir os mapas e criar resistências à cartografia oficial.

\section{METODOLOGIA: TRAJANO TOUR 1847}

Além da obra Buenos Aires Tour (2004) (figura 1), Jorge Macchi realizou uma série de trabalhos artísticos (instalações, pinturas, videoinstalações, painéis etc.) que subsidiam, a partir de seus próprios processos de criação, possibilidades de intervenções em cartas, mapas e outras formas de representar o espaço, problematizando-as.

Por meio da apropriação do processo criativo de Macchi, durante o segundo semestre de 2011, junto às acadêmicas que cursavam a disciplina "Conteúdos e Metodologia de Ensino de Geografia e História" (UDESC), realizou-se uma oficina experimental pelo centro da cidade de Florianópolis denominada "Trajano Tour 1847", tendo como ponto de partida a obra Vista do Desterro, de 1847 (figura 4), do pintor catarinense Victor Meirelles ${ }^{8}$, que ilustra a vista do centro da cidade a partir da Igreja de Nossa Senhora do Rosário e Benedito.

Com inspiração na obra de Jorge Macchi foram reunidos os seguintes materiais para a realização da oficina, cuja proposta era o deslocamento por partes do centro de Florianópolis (SC): uma xerox da obra de Victor Meirelles; um mapa de parte do centro da cidade, retirado do Google Maps; folhas de papel vegetal e traços de canetas coloridas stabilo (vermelho, azul, rosa e lilás) que definiram quatro roteiros. O objetivo da oficina era partir da igreja e da interpretação da obra de Victor Meirelles, exatamente do ponto retratado pelo artista no centro da cidade, no século

escrita de material didático destinado ao curso à distância de Licenciatura em Geografia/Caderno de Geografia Humana da Uniasselvi (SC).

${ }_{8}$ Pintor, desenhista e professor, começou sua trajetória precocemente, realizando paisagens da cidade. Autor de quadros históricos, retratos, panoramas e da mais popular das telas brasileiras, "Primeira Missa no Brasil". Victor Meirelles deixou um extraordinário acervo, minuciosos esboços, estudos em papel e óleos sobre tela. Para maiores detalhes visite o sítio do Museu Victor Meirelles, disponível em: <http://www.museuvictormeirelles.gov.br/bibliografia/\#sthash.IAQ7M5Bk.dpuf>. 
$\mathrm{XIX}$, e criar roteiros a serem percorridos pelas alunas (figura 5). Para isso, foi assinalado um ponto central na folha de papel vegetal que coincidia com a Igreja do Rosário e Benedito e, partindo desse ponto as alunas traçaram segmentos de reta com canetas coloridas no papel vegetal sem qualquer referência do mapa. Após traçarem seus segmentos, a folha de papel vegetal foi sobreposta ao mapa retirado do Google Maps e assim os roteiros foram definidos.

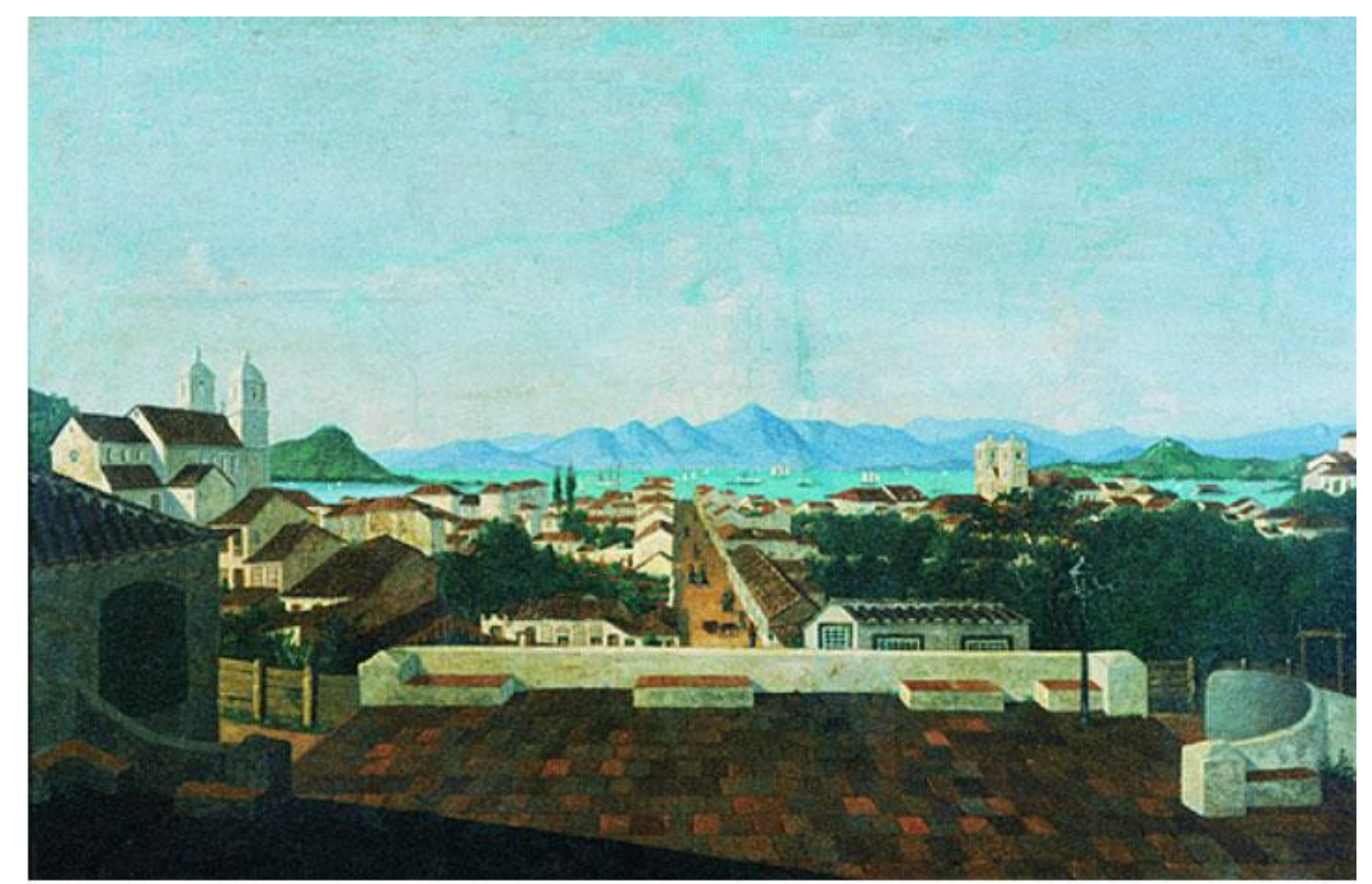

Figura 4 - Vista do Desterro, 1847. Quadro do pintor catarinense Victor Meirelles ${ }^{9}$

A orientação era observar o que chamava atenção de cada aluna, as possibilidades de utilização do mapa, seus limites, suas surpresas, questões relacionadas à arquitetura, ao patrimônio histórico entre outros aspectos. Ou seja, experimentar o mapa e os descaminhos proporcionados pela experiência da deriva.

Jorge Larrosa (2002) pontua que no momento em que vivemos tudo está organizado para que não possamos experimentar as coisas, porque é a informação sobre as coisas que predomina na sociedade e, sobretudo, nos processos escolares. Para este autor "nunca se passaram tantas coisas, mas a experiência é cada vez mais rara" (LARROSA, 2002, p.21).

\footnotetext{
${ }^{9}$ Pintura tirada do Dicionário de Artistas do Brasil:

http://brasilartesenciclopedias.com.br/tablet/nacional/victor_meirelles13.php
}

R. Ra'e Ga - Curitiba, v.30, p.146-164, abr/2014 


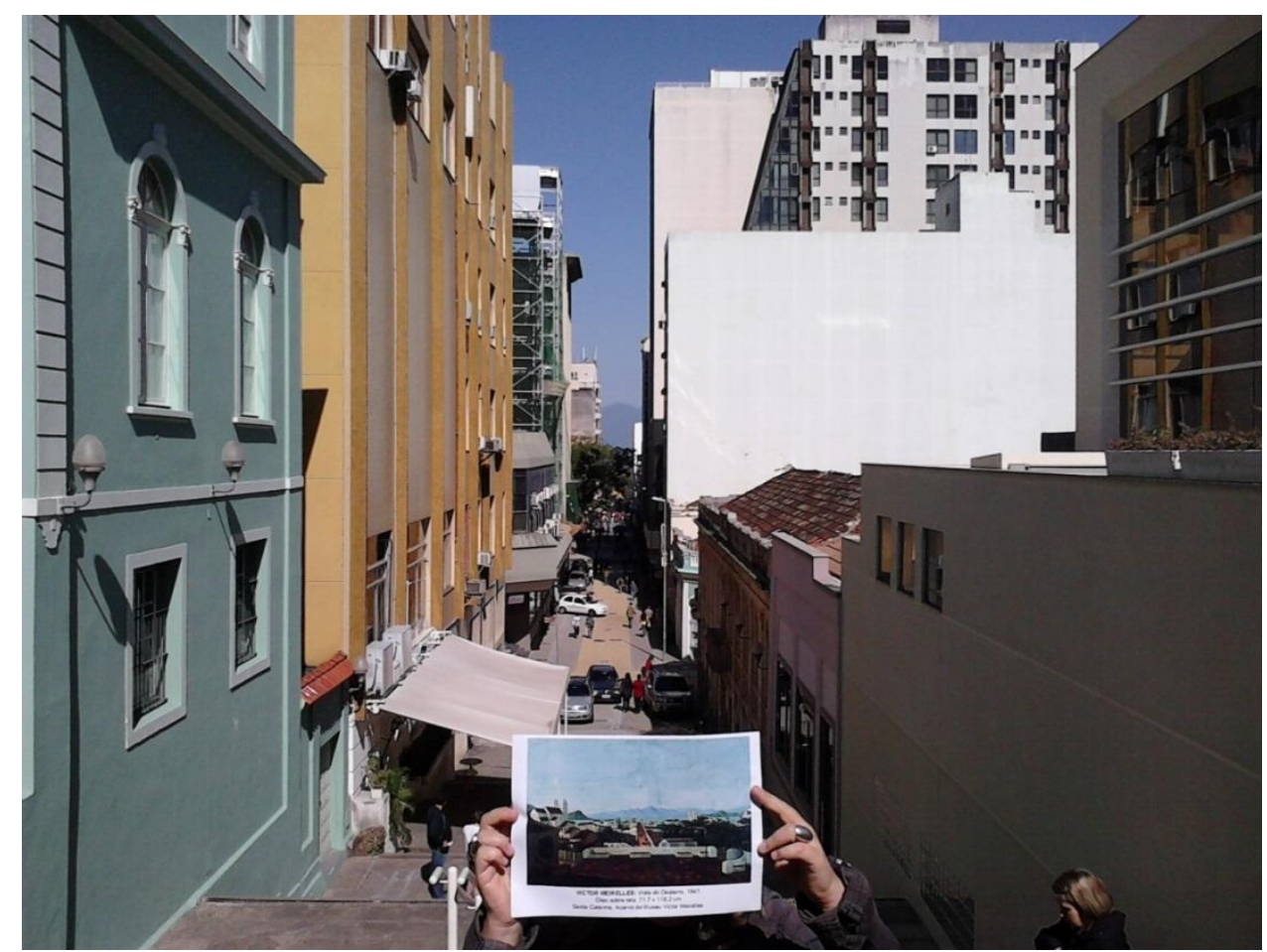

Figura 5 - Vista a partir da escadaria da Igreja do Rosário e Benedito (05/08/2011). No primeiro plano, imagem da obra Vista do Desterro. Foto: Mônica Dias Vieira.

Além de experimentar o mapa, a intenção de juntar essas ferramentas era buscar, de acordo com Guattari (2008, p.170), uma "restauração da cidade subjetiva que indaga tanto os níveis mais singulares das pessoas quanto os níveis mais coletivos" para poder dizer algo sobre a cidade e as formas de apresentar suas ruas, construções, desvios, calçadas, pessoas, surpresas, afetos e sentimentos explorados nos percursos. Pois o espaço considerado é complexo, dinâmico e, concordando com Massey (2008), está sempre em "processo de fazer-se como simultaneidade de estórias-até-agora" (MASSEY, 2008, p.29). Henry Lefebvre (1990) considera o espaço como um produto social e político, porém, "os geógrafos têm procurado analisar essas formas de uma maneira descritiva. O espaço parecia, até recentemente ser um dado, algo natural, mesmo em geografia humana. [...] Na verdade as condições são de complexidade e sutileza" (LEFEBVRE, 1990, p.64).

O desejo de atravessar os espaços passou pelo mapa e pelas possibilidades de abri-lo em sua ordem cartesiana e estática, a fim de poder dizer muito mais sobre alguns pedaços da cidade do que apenas informar e/ou localizar algo. Tomado como referencial de mobilidade, peça integrante do processo de investigação que permeou 
o deslocamento pelo centro da cidade, o mapa, uma vez abertas as formas supostamente inquestionáveis de utilizá-lo, possibilita dizer também algo sobre os elementos subjetivos do espaço. Ou seja, o mapa, neste caso, não foi tomado como limite, mas, ao contrário, foi o disparador do processo reflexivo de apreensão do espaço como simultaneidade (MASSEY, 2008). Um espaço que pode ser dito e interpretado de acordo com a subjetividade daqueles que por ele passaram e perceberam o que antes era invisível aos olhos: formas, cheiros, sentimentos e até mesmo discordâncias entre coisas, prédios que o mapa informava e a realidade.

Foi possível questionar a utilização do mapa como produtor de (in)verdades sobre espaço, assim como a sua abertura através dos encontros com as surpresas que a cidade e os roteiros ofereceram. Afinal, concordamos com Lynch (1988) que, através de seus estudos pioneiros sobre a percepção ambiental em áreas urbanas, realizados na década de 1960, afirma que nas cidades, "a cada instante existe mais do que a vista alcança, mais do que o ouvido pode ouvir, uma composição ou um cenário à espera de ser analisado" (LYNCH, 1988, p.11).

Esta prática também serviu para provocar estranhamentos, pelo fato de alguns caminhos não serem aqueles comumente percorridos pelas alunas em seus trajetos cotidianos. Esse estranhamento foi acentuado pela inquietação em não saber o que fazer quando se tem um percurso aleatório, que se pode explorar à vontade, ou distante do costume dos caminhos conhecidos, e que não se sabe aonde vai dar, como neste relato escrito por uma aluna:

Quis dar uma de esperta, tracei a linha olhando para a reta da escadaria da Nossa Senhora do Rosário, no entanto, ao sobrepor a folha vegetal em cima do mapa das ruas de Florianópolis, minha linha estava direcionada para trás da igreja, sendo assim, lá foi eu na minha peregrinação, em busca do meu ponto final, sem saber ao certo aonde eu iria [...]. Meu ponto final dava em algum lugar que eu não poderia chegar, pois para isso teria que invadir uma casa e chegar ao fundo dela e saber o que me esperava. Mas ao invés disso, dei a volta na quadra e percebi que realmente, não adiantava dar a volta na rua, pois meu ponto de chegada era em algum lugar que eu não saberei nunca. (Aluna B, Ata, 05/08/2011).

\section{ANÁLISE PRELIMINAR DOS RESULTADOS: O DORMINHOCO E REBELDE PASTOR}


A saída em campo, na experimentação com as ferramentas (mapa, obra de Victor Meirelles, roteiro), ganhou uma característica nova ao provocar nos participantes uma experiência cada vez mais rara nas cidades: perder-se nela. Percebe-se isso nos relatos que apontam justamente as dificuldades em utilizar 0 mapa como referência para o deslocamento na cidade: "Eu perguntei para as pessoas que passavam onde estava a rua que eu procurava? Fiquei perdida mesmo com um mapa nas mãos..." (Aluna A, Ata, 05/08/2011).

É possível notar, nessa experiência que a "resistência propriamente artística se dá por meio das sensações e que não pertence a um sujeito, mas transborda" (ONETO, 2007, p.205) para além de uma noção única de leitura do espaço através dos mapas oficiais. Essa noção de "resistência artística" pode ser tomada como potencializadora de questionamentos sobre a cidade, como nesse relato feito após a prática: "[...] você descobre pontos da cidade onde nunca havia parado para observar com calma" (Aluna C, Ata, 05/08/2011). A prática investigativa pode provocar nas alunas, professoras em formação, diferentes sensações como estranhamentos, medos, inquietações que acompanham as descobertas e encontros com a cidade, ao mesmo tempo em que ampliam as leituras do espaço.

Nesse sentido, o trabalho com a cartografia escolar e a intersecção com as experimentações provocadas pela investigação dos processos criativos na arte contemporânea podem ser o convite à elaboração de outras leituras espaciais. Ou seja, olhar para os mapas não como fórmulas prontas ou dadas sobre o espaço, mas para além das suas funções de leitura e comunicação, pensar o espaço na sua potencialidade. Procura-se tirar do mapa e do ensino de cartografia a exclusividade da função instrumentalizadora, agregando a imaginação, a sensibilidade e a criação sobre um espaço complexo a partir das imagens proporcionadas por esse exercício. De acordo com Bachelard (1972, p.14), é preciso se apropriar das "imagens que a vida não prepara, mas que o poeta cria. Trata-se de viver o invivido e abrir-se a uma abertura da linguagem". Concordando também com Seemann (2003), a partir dessas práticas é possível valorizar mais a grafia (mapeamento de uso de uma linguagem) do que $\mathrm{o}$ carto (oficial e técnica) na cartografia (carto-grafia? cartoGRAFIA?), pois o espaço se constitui de outros fatores além das frias geometrias das distâncias físicas. 


\section{CONSIDERAÇÕES FINAIS: GRAFIAS EM DESENVOLVIMENTO}

Os dados apresentados nesta pesquisa em educação e os resultados parciais analisados demonstram que por meio da construção de uma qualidade poética de cartografar o espaço é possível problematizar e investigar o que escapa ou é negligenciado pela cartografia e os modos como essa está sendo ensinada. Ao buscar outras máquinas de pensar (CORAZZA, 2002, p.135) e significar e produzir sentidos para a cartografia e seu ensino na Educação Básica e no Ensino Superior, deseja-se ampliar o universo da pesquisa, bem como aprofundar suas bases teóricas e metodológicas.

Ao retornar ao romance de Sten Nadolny, que abre esta escrita, buscamos apontar as linhas deste processo investigativo que se mantêm abertas, e com ele manter um diálogo que reflete os encantamentos e desejos por esta pesquisa. John Franklin ao voltar para sua vila no leste da Inglaterra, depois de meses em alto-mar, encontra-se com o "dorminhoco e rebelde pastor". Outro trecho do livro de Nadolny serve para encerrar esse círculo de reflexões sobre cartografia, educação e resistência:

A aldeia estava abandonada. Tom Barker estava em Londres com um farmacêutico, para aprender, outros serviam ao exército, muitos tinham ido embora. Na igreja estava o peregrino Bertie, o Lord de Willoughby, e um conjunto de cadeiras vazias. Ainda existia o pastor. O dorminhoco e rebelde pastor. Ele ficava no balcão de White Hart Inn e não dava valor a nada:

- Andar pelo mundo. Para isso não precisa de navio - disse ele -, a terra gira sozinha.

John ouviu isso com paciência.

- Mas você gira com ela - respondeu ele. - Portanto fica no mesmo lugar.

O pastor riu baixinho.

- Você tem que levantar os pés. (NADOLNY, 1989, p. 99).

\section{REFERÊNCIAS}

BACHELARD, Gaston. A poética do espaço. Rio de Janeiro: Eldorado, 1972.

BONDIA, Jorge Larrosa. Notas sobre a experiência e o saber de experiência. Revista Brasileira de Educação [online], n.19, p. 20-28, 2002.

CANÇADO, Wellington; MARQUEZ, Renata. Índice de miopia (myopia index). In: SIMPÓSIO INTERDISCIPLINAR: VIGILÂNCIA, SEGURANÇA E CONTROLE 
SOCIAL NA AMÉRICA LATINA, 1, 2009, Curitiba. Anais... Curitiba: Pontifícia Universidade Católica do Paraná, p. 538-564, 2009.

CORAZZA, Sandra Mara. Noologia do currículo: vagamundo, o problemático, e assentado, o resolvido. Educação \& Realidade, v. 27, n. 2, p. 131-142, 2002.

DEL RIO,Vicente; OLIVEIRA, Lívia de (org). Percepção e Representação do Espaço Geográfico. In: OLIVEIRA, Lívia de. Percepção ambiental: a experiência brasileira. 2 ed. São Paulo: Studio Nobel, 1999, p.187- 212.

GIRARDI, Gisele. Mapas desejantes: uma agenda para a Cartografia Geográfica. Pró-Posições, Campinas, v. 20, n. 3 (60), p.147-157, 2009.

- Cartografias alternativas no âmbito da educação escolar. Revista Geográfica de América Central, Número Especial do EGAL, Costa Rica, p. 1-15, 2011.

GUATTARI, Félix. Caosmose: um novo paradigma estético. 5. ed. São Paulo: Ed. 34, 2008.

LEFEBRVE, Henri. Conversa com Henri Lefebvre. Espaço \& Debates, São Paulo, n. 30, p. 61-69, 1990.

LYNCH, Kevin. A imagem da cidade. São Paulo: Martins Fontes, 1988.

MASSEY, Doreen B. Pelo espaço: uma nova política de espacialidade. Rio de Janeiro: Bertrand Brasil, 2008.

MARQUEZ, Renata Moreira. Geografias Portáteis: arte e conhecimento espacial. 2009. Tese (Doutorado em Geografia) - Instituto de Geociências, Universidade Federal de Minas Gerais, Belo Horizonte.

NADOLNY, Sten. A descoberta da lentidão. Rio de Janeiro: Rocco, 1989.

PEREZ-BARREIRO, Gabriel. Jorge Macci: exposição monográfica. Porto Alegre: Fundação Bienal do Mercosul, 2007.

PREVE, Ana Maria Hoepers. Mapas, prisão e fugas: cartografias intensivas em educação. 2010. Tese (Doutorado em Educação) - Faculdade de Educação, Universidade Estadual de Campinas, Campinas.

RIEUX, Bernardo. O abecedário de Gilles Deleuze, s/d. Disponível em < http://www.oestrangeiro.net/esquizoanalise/67-o-abecedario-de-gilles-deleuze>. Acesso em 20/02/2014.

SEEMANN, Jörn. Mapas, mapeamentos e a cartografia da realidade. Geografares, Vitória, ES, n. 4, p. 49-60, 2003. 
Arte, conhecimento geográfico e leitura de imagens: o geógrafo de Vermeer. Pró-Posições, Campinas, v. 20, n. 3 (60), p. 43-60, 2009.

OLIVEIRA JÚNIOR, Wenceslao M. de. Grafar o espaço, educar os olhos. Rumo a geografias menores. Pró-Posições, Campinas, v. 20, n. 3(60), p.17-28, 2009. v.47, p.1-20, 2011.

A educação visual dos mapas. Revista Geográfica da América Central,

OLIVEIRA JÚNIOR, Wenceslao M. de; GIRARDI, Gisele. Diferentes linguagens no ensino de Geografia. In: ENCONTRO NACIONAL DE PRÁTICAS DE ENSINO DE GEOGRAFIA, XI, Goiânia. Anais... Goiânia: Universidade Federal de Goiás, s/p, 2011. (CD-ROM)

ONETO, Paulo Domenech. A que e como resistimos: Deleuze e as artes. In: LINS, Daniel (Org.) Nietzsche/Deleuze: Arte, resistência. Rio de Janeiro: Forense Universitária; Fortaleza, CE: Fundação de Cultura, Esporte e Turismo, 2007, p. 198211.

TUAN, Yi-Fu,. Topofilia : um estudo da percepção, atitudes e valores do meio ambiente. São Paulo: Difel, 1980.

1983.

Espaço e lugar: a perspectiva da experiência. São Paulo: Difel, 